\title{
Study on the "Task-Oriented" Teaching Reform of Vocational Pharmaceutical Marketing Courses
}

\author{
Quanli Wu \\ Hunan Food and Drug Vocational College \\ Changsha, China
}

\begin{abstract}
The pharmaceutical marketing course is one of the most important contents to realize the objective of professional talents cultivation in medicines and drugs, and the course construction has been generally concerned by all colleges. However, due to the late starting of the course construction and the special industry background, the current course teaching efficiency still remains to be improved and the "task-oriented" teaching reform should be practically deepened so as to effectively realize the functional objectives of courses.
\end{abstract}

Keywords—task-oriented; marketing; course

\section{INTRODUCTION}

Course is the basic unit of teaching and the quality of teaching is directly related to the realization of objectives of talents cultivation of various types. For the vocational colleges, the teaching of professional core courses plays the crucial role. In recent years, the pharmaceutical marketing courses spring up and rapidly become the indispensable core courses of relevant majors. Through the research on teaching of this course set by relevant majors in six vocational colleges in Hunan Province and the investigation on the job requirements in 16 enterprises such as pharmaceutical manufacturing enterprises, pharmaceutical wholesale enterprises and pharmaceutical retail enterprises, the author thinks that the deepening of teaching reform of vocational pharmaceutical marketing courses and the implementation of course teaching based on "task-orientation" have urgent and important practical significance.

\section{CONSTRUCTION STATUS OF VOCATIONAL}

PHARMACEUTICAL MARKETING COURSES AND THE ANALYSIS ON TEACHING STATUS

\section{A. There Generally Exists the Miscellaneous Theories and} Practice Lacking of Authenticity in the Teaching Contents

The overall starting of the construction of vocational pharmaceutical marketing courses is late and the basic knowledge and theories of marketing take up large quantity of items and space while the practical contents closely related to the pharmaceutical marketing with pertinence are apparently less which is highlighted as that the theoretical knowledge logical system of course contents is complete and complex while there still exists the dispersion, segmentation, not enough integration and apparent lacking of real cases originated in the enterprises and market in practical system which result in that the practical teaching contents must lack real experience and feelings on the scene and cause the practical training of students to be divorced from reality.

\section{B. The Teaching Modes Are Generally Too Traditional While the New Theories Are Difficult to Be Implemented}

The teaching of vocational pharmaceutical marketing courses generally adopts the traditional method of theory teaching plus few cases analysis and over intensifies the teacher-directed but the dominant position of students is not manifested. The course teaching can't take program as medium, cases as supporting and enterprise as background a, can't train the vocational abilities through activity tasks and can't realize the integration of "teaching, learning and doing". In addition, the evaluation method of course teaching is single and simple which still mainly adopts the method of written examinations to organize the students to participate in the theory tests and also take the routine evaluations so as to comprehensively evaluate the academic results of students.

\section{The Teaching Method Is Generally Single and Insufficient Simultaneous Implementation of Multiple Methods}

The vocational pharmaceutical marketing courses need to cultivate the students to possess certain theoretical attainment of marketing and more importantly, cultivate the students with "practical" skills for the work of pharmaceutical marketing. However, currently, the schools still follow the traditional teaching methods and arrange the most of class hours in the closed classroom and take the repetition of what says in the books and statement of knowledge from teachers as main methods but can't design the teaching according to the features of course nature which results in that many mature and effective teaching methods are neglected and the course teaching efficiency and effects can't be improved.

\section{OPTIMIZATION OF “TASK-ORIENTATED” TEACHING DESIGN FOR PHARMACEUTICAL MARKETING COURSES}

The significance, particularity and sensibility of pharmaceuticals industry decide that the pharmaceutical market is completely different from other commodity markets, which possesses its own special activity routines and industry criterions. Therefore, firstly, instead of complete indiscriminately copy of relevant achievements of marketing, the construction and teaching reform of pharmaceutical marketing courses shall conduct reasonable sublation; 
secondly, scientifically analyze the main features and essential requirements, independently develop new approaches to construct the content system; what's more, intensify the practical teaching, enhancing the comprehensive abilities of students. However, the course theory of "task-oriented" is currently widely accepted by vocational education world which not only emphasizes on the combination of teaching progress and working process, but also puts more and more attention on the integration of task, vocational situations and teaching contents so as to achieve the connection of course teaching and position knowledge and abilities. Therefore, the optimization of course teaching and designing based on the "task-orientated" has important practical significance.

\section{A. Scientifically Establish the Theory for Course Development and Design}

The development of vocational pharmaceutical marketing courses should base on the enhancing of pertinence of course teaching, effectiveness of service industry and the universality of interaction between schools and enterprises to promote the optimization of course content system and innovation of course teaching modes so as to practically improve the course construction and teaching quality which is beneficial to the cultivation of pharmaceutical marketing talents. Therefore, the course content design should take the vocational post demands as starting point, take the formative education as emphasis and take the intensification of practical application as objective to fully manifest the vocational education theory with integration of theory and practice. Accord with the principle of "integration of teaching, learning and doing" to take the program as carrier and take the typical tasks and work activities as learning situations to realize the connection of course contents and vocational standards, the combination of teaching places and work positions, interchange of student identification and the role of employees and the combination of teaching environment and vocational situations to truly implement the combination of work and learning to the practice. At the same time, through program-based course design, promote the self-regulated and ubiquitous learning of students, promote the learning abilities and attainment and guarantee the quality of talent cultivation so as to improve the employment competitiveness.

\section{B. Reasonably Establish the Course Teaching Objectives}

The vocational pharmaceutical marketing courses should strictly implement the basic requirements of "quality-oriented and ability as core", insist the modern marketing concept of "customer-oriented" and cultivate the students to develop the favorable professional dedication and professional ethics, possess certain abilities for the collection and processing of information, analysis and solving of problems and communication and expression, technical skills for proficient occupation of pharmaceutical marketing and certain basis for continuous learning, self-development and entrepreneurship through learning and practice so as to provide necessary knowledge, skills and attainment services for the students to engage in the relevant vocational activities.

\section{Effectively Establish the Course Teaching Contents}

The contents of vocational pharmaceutical marketing courses should base on the investigation of job requirements of pharmaceutical marketing and the analysis results of the knowledge and ability structure of pharmaceutical marketing personnel to take the specification requirements of professional talents and course objectives as the essential foundations, accord with the course design theory to conduct the deconstruction and reconstruction of teaching contents, break through the traditional content system of marketing courses and adopt the form with "program" plus "typical tasks" to conduct overall planning and design. Based on the large quantity of investigations and analysis, this course contents construct 11 program carriers and 39 typical tasks and each typical task presents the teaching contents with one comprehensive activity so as to realize the three dimensional composition of course teaching system.

\section{CONCLUSION}

The teaching design of pharmaceutical marketing courses is guided by the "task-orientated" to deepen the reforms on course teaching contents, teaching modes, teaching methods and evaluation measures etc which is the effective measure to improve the teaching efficiency of vocational pharmaceutical marketing courses and to improve the cultivation quality of skilled talents with high quality.

\section{A. The Design of Teaching Situations should Approach to the Actualization}

The course teaching should base on the practice process of pharmaceutical marketing, take the accomplishment of product marketing planning schemes as the principal line to organize teaching and form the teaching mode dominated by program teaching and task driving and accomplish the "programorientated theory teaching, vocational practical skills and integration of teaching, learning and doing" through various forms of teaching methods and means selection so as to better cultivate the comprehensive abilities for marketing of students. At the same time, take full advantage of the classrooms with integration of theory and practice, simulating pharmacy and off-campus practice bases established by the school to orderly develop the theory teaching, situational simulation and practical operation and to implement the cultivation with the integration of work and learning.

\section{B. The Selection of Teaching Methods and Means should Be Diversified}

According to the reform achievements of higher vocational education, combining with the course teaching objectives and the design features of course contents and the learning behavior habits of higher vocational college students, the selection and application of the course teaching methods and means are mainly based on the theory of working situations, on the subject of students and the leading role of teacher to adopt the teaching method with integration of "teaching, learning and doing" and let the students "do in learning and learn in doing". To this end, this course will base on the specific conditions of teaching contents to comprehensively 
select the project teaching method, case teaching methodology, task-driven method, teacher lecturing method and other teaching methods such as student group discussion, role playing method and practical performance method etc; at the same time, give full play to the functions of cyber space of courses and teaching space of teachers and students, systemically construct the teaching resources dominated by the typical real cases, practical training program and classic marketing cases etc and rely on the multimedia technology for aided teaching.

\section{The Training of Practical Skills should Be Modularized}

The course should combine with ability requirements of the core positions of pharmaceutical marketing and the actual conditions of students of the higher vocational medicines and drugs majors to conduct the modularized setting to all basic skills and core skills relevant to the courses, that is, to constitute the series of skill program from single item to the comprehensiveness first according to the skill contents and then conduct the classification setting to specifically develop the systemic professional skill training and comprehensive skill training which is not only the demands for students to adapt to the positions, but also is the demands for the concern of long-term development of students. At the same time, during the modularized process of skill program, consciously conduct the organic combination of cultivation of communication ability, investigation and analysis abilities and capacity to operate computer of student with professional abilities so as to form the training modules with certain comprehensiveness and improve the skill attainment and comprehensive abilities of students for problems finding, analysis and solving through the implementation of class teaching, practical training and maneuver, social practice and enterprise internship and other approaches.

\section{The Evaluation should Realize Multivariate Combination}

As core course, this course adopts the method combining with formative evaluation and summative evaluation for the joint participation of teachers and students to realize the unification of knowledge and skill examination and evaluation as well as process and result examination and evaluation. The composition of student course results is that the formative evaluation accounts for $30 \%$ and the summative evaluation accounts for $70 \%$. Thereinto, the formative evaluation mainly includes the classroom performance and practical operation and adopts the method of self-evaluation and mutual evaluation of students and the evaluation of teachers to evaluate the results. At the same time, encourage and support students to participate in the qualification tests for medicine purchasers and sellers and the medical apparatus and instruments purchasers and sellers and give play to the evaluation functions of social examinations.

\section{REFERENCES}

[1] Wu Quanli. Study on the Teaching Strategies for Marketing Courses of Vocational Colleges-Based on the Background of "Web-based Learning Space for Teacher and Student Education" [J]. Vocational and Technical Education Forum. 2014 (10).
[2] Luo Guosheng, Sun Xi. Research on the Teaching Reform on Pharmaceutical Marketing Course in vocational colleges[J]. Research in Teaching. 2010 (2)

[3] Zhang Wenling, Wang Yiyan. Study on the Cultivation Modes for Marketing Talents of Colleges [J]. Journal of Youjiang Medical College for Nationalities. 2006 (4).

[4] Xu Wen, Ma Chenyan, Mo Yingning, Pu Xiaofang. Practice on the Construction of Course System for Pharmaceutical Marketing [J]. Intemet Fortune. 2009 (4).

[5] Zhang Nan. Study on the Teaching Reform of Pharmaceutical Marketing Courses[J]. Science and Education Frontier. 2009 (4).

[6] Duan Wenhai. Study on the Reform on Pharmaceutical Marketing Courses of Higher Vocational Colleges [J]. Journal of Modern Food and Pharmaceuticals. 2006 (5).

[7] Chen Yongxian. Study on the Construction of Professional Teaching Resource Library for Vocational Education[J]. Vocational and Technical Education Forum. 2011 (8). 